\title{
Tinjauan Kelengkapan Pengisian Resume Medis Berdasarkan Elemen Penilaian Akreditasi SNARS 1.1 Di RSUD Kembangan
}

\section{Overview of Completeness of Medical Resume Filling Based on Elements SNARS 1.1 Accreditation Assessment}

\author{
Muammar Dzachwani ${ }^{1}$, Deasy Rosmala Dewi ${ }^{2}$, Puteri Fannya ${ }^{3}$, Laela Indawati ${ }^{4}$ \\ 1,2,3,4 Universitas Esa Unggul \\ Jalan Arjuna Utara No.9, Kb. Jeruk, Kec. Kb. Jeruk, Kota Jakarta Barat \\ *e-mail korespondensi: muammardzc@gmail.com
}

\begin{abstract}
Abstrak
Kelengkapan resume medis digunakan untuk dasar pembuatan laporan intern dan ekstern rumah sakit. Tujuan dari penelitian ini adalah untuk mengetahui gambaran kelengkapan pengisian resume medis berdasarkan elemen penilaian akreditasi SNARS 1.1. Metode penelitian yang digunakan adalah metode analisis deskriptif dan teknik pengumpulan data adalah observasi, analisis kuantitatif, dan pedoman wawancara. Berdasarkan hasil penelitian mengenai Standar Prosedur Operasional pengisian resume medis di Rumah Sakit Umum Daerah Kembangan Jakarta sudah ada, dimana terdapat 3 prosedur yang belum dijalankan yaitu tidak adanya buku catatan yang mencatat mengenai resume yang belum diisi, melengkapi resume medis dilakukan di ruang rawat inap, belum tersedianya buku catatan yang mencatat resume medis yang belum diisi. Kelengkapan resume medis $91,59 \%$ dari 90 resume medis dan tidak lengkap 8,41\%. Dampak dari ketidaklengkapan resume medis membuat angka review rekam medis menjadi tidak bagus, bagi pasien bpjs klaim menjadi terhambat, membuat proses kelanjutan pengobatan terganggu karna riwayat pengobatan pasien tidak lengkap, tidak lengkap resume juga berpengeraruh terhadap akreditasi rumah sakit. Perlunya disosialisasikan kembali mengenai Standar Operasional Prosedur dan perlu ketegasan dari pihak Direktur rumah sakit agar tingkat kedisiplinan dalam pengisian resume medis dapat terlaksana dengan baik dan tepat waktu.
\end{abstract}

Kata kunci: Kelengkapan ,Pengisian, Resume Medis, Berdasarkan SNARS 1.1

\begin{abstract}
The completeness of the medical resume is used as the basis for making internal and external hospital reports. The purpose of this study was to describe the completeness of filling out a medical resume based on the elements of the SNARS 1.1 accreditation assessment. The research method used is descriptive analysis method and data collection techniques are observation, quantitative analysis, and interview guidelines. Based on the results of research regarding Standard Operating Procedures for filling out medical resumes at the Kembangan Hospital Jakarta, there are 3 procedures that have not been carried out, namely the absence of a notebook that records the resume that has not been filled in, completing the medical resume in the inpatient room, and the unavailability of notebook. which records medical resumes that have not been filled out. Completeness of medical resume accreditation assessment elements $91.59 \%$ of 90 medical resumes and $8.41 \%$ incomplete. The impact of incomplete medical resumes makes the number of medical record reviews not good, for BPJS patients claims are hampered, making the continuation process of treatment disrupted because the patient's medical history is incomplete, incomplete resumes also affect hospital accreditation. The need for resocialization regarding Standard Operating Procedures and the need for firmness from the hospital Director so that the level of discipline in filling out medical resumes can be carried out properly and on time.
\end{abstract}

Keywords: Completeness ,of Medical Resume, Filling, Based on SNARS 1.1.

p-ISSN: | e-ISSN: 2807-2596

website: ijhim.stikesmhk.ac.id/index.php/ 


\section{PENDAHULUAN}

Upaya yang harus dilakukan rumah sakit untuk mencapai pelayanan kesehatan yang bermutu yaitu wajib melakukan akreditasi, Akreditasi bertujuan untuk : meningkatkan mutu pelayanan rumah sakit dan melindungi keselamatan pasien rumah sakit, meningkatkan perlindungan bagi masyarakat, sumber daya manusia di rumah sakit dan rumah sakit sebagai institusi, mendukung program pemerintah di bidang kesehatan, dan meningkatkan profesionalisme rumah sakit Indonesia di mata internasional (RI, 2017).

Menurut UU 44 Tahun 2009, Rumah Sakit adalah institusi pelayanan kesehatan yang menyelenggarakan pelayanan kesehatan perindividu secara paripurna yang menyediakan pelayanan rawat inap, rawat jalan, dan gawat darurat. Dalam menyelenggarakan semua kegiatan rumah sakit wajib melakukan pencatatan dan pelaporan dalam bentuk Sistem Informasi Manajemen Rumah Sakit(Indonesia, 2009).

Rekam medis adalah berkas yang menyatakan siapa, apa, mengapa, dimana, kapan dan bagaimana pelayanan yang diperoleh seorang pasien selama dirawat atau menjalani pengobatan. Peraturan Menteri Kesehatan Republik Indonesia Nomor: 269/MENKES/PER/III/2008 menyatakan Rekam Medis adalah berkas yang berisikan catatan dan dokumen tentang identitas pasien, pemeriksaan, pengobatan, tindakan dan pelayanan lain yang telah diberikan kepada pasien (RI, 2008).

Ringkasan pulang (resume atau discharge summary) adalah ringkasan dari seluruh masa perawatan dan pengobatan pasien sebagaimana yang telah diupayahkan oleh para tenaga kesehatan dan pihak terkait. Umumnya informasi yang terdapat di dalamnya adalah mengenai jenis perawatan yang diterima pasien, reaksi tubuh terhadap pengobatan, kondisi saat pulang serta tindak lanjut pengobatan setelah pulang perawatan (Hatta, 2014).

Ringkasan pulang yang dibuat oleh dokter atau dokter gigi yang melakukan perawatan kepada pasien sebagai ringkasan pelayanan. Isi ringkasan pulang sekurangkurangnya memuat : identitas pasien, diagnosis masuk dan indikasi pasien dirawat, ringkasan hasil pemeriksaan fisik dan penunjang, diagnosis akhir, pengobatan dan tindak lanjut, dan nama dan tanda tangan dokter atau dokter gigi yang memberikan pelayanan kesehatan (Kemenkes RI, 2008).

Kelengkapan pada suatu rekam medis ialah hal yang sangat penting dilakukan setelah pelayanan atau tindakan medis terhadap pasien dan harus dilengkapi kurang dari 1x24 jam. Kelengkapan rekam medis akan memudahkan tenaga kesehatan dalam memberikan pelayanan kesehatan atau tindakan medis. Kelengkapan rekam medis bila tidak dilengkapi akan menyulitkan petugas pelayanan dalam memberikan pelayanan medis atau tindakan medis karena tenaga medis harus mengetahui riwayat pasien, tindakan apa saja yang telah diberikan sebelumnya dan pemberian obat terhadap pasien (RI, 2008).

Berdasarkan penelitian yang dilakukan oleh Putri Riska Laka di Rumah Sakit Panti Wilasa Citarum Semarang persentase kelengkapan pengisian lembar ringkasan masuk keluar kasus bedah dari sampel sebanyak 61 berkas sebesar 86,39\%. Faktor yang memengaruhi ketidaklengkapan berkas pada kasus bedah yaitu kurang telitinya petugas yang mengisi lembar ringkasan masuk keluar, kurangnya sosialisasi kepada dokter dan perawat tentang pentingnya kelengkapan pengisian ringkasan masuk keluar serta belum adanya deskripsi yang lebih rinci tentang pengisian lembar ringkasan masuk keluar oleh dokter maupun perawat pada lembar SPO di RS Panti Wilasa Citarum Semarang (Laka, 2017).

Hasil penelitian yang dilakukan oleh Dwinta Septanty Di Rumah Sakit Umum Kabupaten Tangerang memiliki rata-rata kelengkkapannya sebesar $96,70 \%$ dan ketidaklengkapannya sebesar 3,30\%. Berdasarkan 4 komponen analisis kuantitatif resume medis, komponen yang tertinggi kelengkapannya adalah identitats pasien sebesar $100 \%$ dan komponen yang terendah kelengkapannya adalah isi resume medis sebesar 90\% (Septanty, 2016).

$$
\text { Rumah Sakit Umum Daerah }
$$

Kembangan merupakan rumah sakit tipe D yang beralamat di Jl. Topas Raya Blok FII No.03, RT.15/RW.7, Meruya Utara, Kec. Kembangan, Kota Jakarta Barat, memiliki 50 tempat tidur pasien rawat inap. Pasien rawat inap RSUD Kembangan rata rata per bulan yaitu 147 pasien.

Hasil observasi awal peneliti di bulan Januari dengan 30 resume medis dapat dihasilkan, Dari 30 resume medis, dihasilkan resume medis lengkap 4 berkas dengan 
persentase $13,33 \%$ dan yang tidak lengkap sebanyak 26 berkas dengan persentase $86,66 \%$. Dari ketidaklengkapan resume medis berdampak bagi petugas rekam medis, karena petugas harus mengembalikan resume medis ke dokter dengan lama waktu 2x24 jam. Bagi pasien, karena pasien harus menggu resume medis kembali setelah dilengkapi. Bagi rumah sakit, karena akan berpengaruh terhadap akreditasi rumah sakit. Berdasarkan latar belakang di atas, penulis melakukan penelitian tentang Tinjauan Kelengkapan Pengisian Resume Medis Berdasarkan Elemen Penilaian Akreditasi SNARS 1.1 di RSUD Kembangan.

\section{METODE PENELITIAN}

Metode penelitian yang dilakukan adalah metode deskriptif kuantitatif. Populasi pada penelitian ini adalah seluruh formulir resume medis rawat inap RSUD Kembangan pada Triwulan IV yaitu bulan OktoberDesember tahun 2020, dengan menggunakan perhitungan rumus slovin, sampel pada penelitian ini yaitu resume medis sebanyak 90 resume medis, cara pengambilan data dengan systematic random sampling. Penelitian dilakukan di unit rekam medis RSUD Kembangan. Penelitian ini dilakukan pada bulan Januari - Agustus tahun 2021.

\section{HASIL DAN PEMBAHASAN}

\section{SPO Pengisian Resume Medis}

Standar Prosedur Operasional (SPO) diatur dalam Undang-Undang No. 44 Tahun 2009 tentang Rumah Sakit Pasal 13 Ayat 3 menjelaskan bahwa setiap tenaga kesehatan yang bekerja di rumah sakit harus bekerja sesuai dengan Standar Profesi, Standar Pelayanan Rumah Sakit, Standar Prosedur Operasional yang berlaku, etika profesi menghormati hak pasien dan mengutamakan keselamatan pasien (Indonesia, 2009).

Berdasarkan hasil wawancara SPO pengisian resume medis terdapat beberapa prosedur yaitu: Pada prosedur rekam medis pasien rawat inap di cek untuk mengetahui sudah diisi atau belum, sudah dijalankan pengecekan oleh petugas rekam medis berkas resume medis yang sudah diisi atau belum. Menurut Permenkes RI No. 269 Tahun 2008 dalam Pasal 4 Resume medis harus dibuat oleh dokter atau dokter gigi yang melakukan perawatan pasien yang sekurang- kurangnya memuat : identitas pasien, diagnosis masuk dan indikasi pasien dirawat, ringkasan hasil pemeriksaan fisik dan penunjang, diagnosis akhir, pengobatan dan tindak lanjut, dan nama dan tanda tangan dokter atau dokter gigi yang memberikan pelayanan Kesehatan.

Pada prosedur rekam medis yang formulir resumenya belum di isi dipisahkan dan dicatat pada buku resume ini belum dijalankan dikarenakan tidak adanya buku catatan yang mencatat mengenai resume yang belum diisi.

Pada prosedur melengkapi formulir resume hanya boleh dikerjakan di ruang unit rekammedis belum dijalankan, dikarenakan melengkapi resume medis dilakukan di ruang rawat inap.

Pada prosedur pada buku resume nama pasien, nomor rekam medis dan nama dokter dicoret jika resume telah dilengkapi belum dijalankan dikarenakan belum tersedianya buku catatan yang mencatat resume medis yang belum diisi.

Dari hasil observasi yang telah dilakukan oleh Sri Ani mengenai standar operasional prosedur (SPO) pengisian resume medis di Rumah Sakit Haji Pondok Gede diketahui bahwa sudah terdapat SPO yang mengatur tentang pengisian resume medis dengan ketentuan untuk melengkapi pengisian resume medis dengan ketentuan untuk melengkapi pengisian resume medis selambat-lambatnya 2x24 jam setelah pasien pulang. Standar operasional prosedur (SPO) sudah disosialisasikan terakhir pada 2016 (Ani, 2017).

\section{Kelengkapan Pengisian Resume Medis Berdasarkan Elemen Penilaian Akreditasi SNARS 1.1}

Tabel 1. Rekapitulasi Analisis Kuantitatif Resume Medis

\begin{tabular}{|c|c|c|c|}
\hline No & Kriteria Analisis & $\mathbf{n}$ & $\%$ \\
\hline & $\begin{array}{ll}\text { A. } & \text { Identifikasi } \\
\text { Pasien } & \end{array}$ & & \\
\hline 1. & Nama Pasien & 90 & $100 \%$ \\
\hline 2. & No.Rekam Medis & 89 & $99 \%$ \\
\hline 3. & Tanggal Lahir & 90 & $100 \%$ \\
\hline \multirow[t]{3}{*}{4.} & Jenis Kelamin & 88 & $98 \%$ \\
\hline & Average & 89,25 & $99,16 \%$ \\
\hline & $\begin{array}{l}\text { B. Catatan Yang } \\
\text { Penting }\end{array}$ & & \\
\hline 1. & Asal Rungan & 66 & $73 \%$ \\
\hline 2 & Ruangan & 81 & $90 \%$ \\
\hline 3 & Tanggal Masuk & 90 & $100 \%$ \\
\hline 4 & Tanggal Keluar & 87 & $97 \%$ \\
\hline
\end{tabular}

p-ISSN: | e-ISSN: 2807-2596

website: ijhim.stikesmhk.ac.id/index.php/ 


\begin{tabular}{|c|c|c|c|}
\hline No & Kriteria Analisis & $\mathbf{n}$ & $\%$ \\
\hline & Pemeriksaan & & \\
\hline 5 & Fisik(SNARS 1.1) & 90 & $100 \%$ \\
\hline 6 & Hasil Laboratorium & 87 & $97 \%$ \\
\hline 7 & Diagnosa Masuk & 90 & $100 \%$ \\
\hline 8 & Diagnosa Utama & 89 & $99 \%$ \\
\hline 9 & $\begin{array}{l}\text { Diagnosa Skunder } \\
\text { (SNARS 1.1) }\end{array}$ & 66 & $73 \%$ \\
\hline 10 & $\begin{array}{l}\text { Indikasi dirawat } \\
\text { (SNARS 1.1) }\end{array}$ & 58 & $64 \%$ \\
\hline 11 & $\begin{array}{l}\text { Prosedure } \\
\text { Terapi/Tindakan } \\
\text { Invasif( SNARS 1.1) }\end{array}$ & 68 & $75 \%$ \\
\hline 12 & $\begin{array}{l}\text { Obat yang diberikan( } \\
\text { SNARS 1.1) }\end{array}$ & 89 & $99 \%$ \\
\hline 13 & $\begin{array}{ll}\text { Kondisi Pasien } & \text { saat } \\
\text { ini(SNARS 1.1) } & \\
\end{array}$ & 85 & $94 \%$ \\
\hline 14 & $\begin{array}{l}\text { Prognosis/Perkemba } \\
\text { ngan Pasien(SNARS } \\
1.1 \text { ) }\end{array}$ & 88 & $98 \%$ \\
\hline 15 & $\begin{array}{l}\text { Anjuran } \\
1.1 \text { (SNARS }\end{array}$ & 69 & $76 \%$ \\
\hline 16 & $\begin{array}{l}\text { Kondisi } \quad \text { Pasien } \\
\text { Keluar(SNARS 1.1) }\end{array}$ & 85 & $94 \%$ \\
\hline \multirow[t]{3}{*}{17} & $\begin{array}{l}\text { Tanda Tangan } \\
\text { Pasien/Keluarga(SN } \\
\text { ARS 1.1) }\end{array}$ & 65 & $72 \%$ \\
\hline & Average & $\mathbf{7 9 , 5 8}$ & $88,43 \%$ \\
\hline & $\begin{array}{l}\text { C.Autentikasi } \\
\text { Penulis } \\
\end{array}$ & & \\
\hline 1 & Nama Dokter & 88 & $98 \%$ \\
\hline 2 & Tanda Tangan & 89 & $99 \%$ \\
\hline \multirow[t]{3}{*}{3} & Tanggal & 87 & $97 \%$ \\
\hline & Average & 88 & $97,77 \%$ \\
\hline & $\begin{array}{l}\text { D. Catatan Yang } \\
\text { Baik }\end{array}$ & & \\
\hline 1 & Tidak Ada Coretan & 88 & $98 \%$ \\
\hline 2 & Tidak Ada Tip-ex & 90 & $100 \%$ \\
\hline 3 & $\begin{array}{l}\text { Tidak Ada Bagian } \\
\text { Kosong }\end{array}$ & 41 & $45 \%$ \\
\hline & Average & 73 & $\mathbf{8 1 \%}$ \\
\hline $\mathbf{A V}$ & RAGE A-D & 82,45 & $91,59 \%$ \\
\hline
\end{tabular}

Berdasarkan Tabel 1 diatas menunjukan bahwa hasil rekapitulasi analisis kuantitatif formulir resume medis dari 90 resume medis yang dianalisa rata-rata kelengkapan 91,59\%. Persentase pada komponen Identifikasi Pasien $99,16 \%$, Catatan yang Penting 88,43\%, Autentikasi Penulis $97,77 \%$, dan Catatan yang Baik $81 \%$.

\section{Resume Medis Berdasarkan Identifikasi Pasien}

Dari hasil perhitungan, persentase kelengkapan formulir 90 resume medis pada
Identifikasi Pasien rata-rata kelengkapannya 99,16\% dan yang tidak lengkap $0,75 \%$. Pada Identifkasi Pasien terdapat persentase yang terendah yaitu pada item jenis kelamin sebesar 98\%, Nomer Rekam, dan komponen yang tertinggi pada item Nama, dan Tanggal Lahir $100 \%$.

\section{Resume Medis Berdasarkan Catatan yang Penting}

Dari hasil perhitungan, persentase kelengkapan formulir 90 resume medis pada catatan yang penting rata-rata kelengkapannya $88,43 \%$ dan yang tidak lengkap $11,57 \%$. Pada Catatan yang Penting terdapat persentase yang terendah yaitu pada item indikasi dirawat sebesar 64\%, dan persentase kelengkapan tertinggi pada item tanggal masuk, pemeriksaan fisik (SNARS 1.1), dan diagnosa masuk sebesar $100 \%$.

\section{Resume Medis Berdasarkan Autentikasi Penulis}

Dari hasil perhitungan, persentase kelengkapan formulir 90 resume medis pada autentikasi penulis rata-rata kelengkapannya $97,77 \%$ dan yang tidak lengkap 3,33\%. Pada autentikasi penulis terdapat presentasi yang terendah yaitu pada item tanggal sebesar 97\%, dan persentase kelengkapan tertinggi pada item tanda tangan 99\%.

\section{Resume Medis Berdasarkan Catatan yang Baik \\ Dari hasil perhitungan, persentase} kelengkapan formulir 90 resume medis pada catatan yang baik rata-rata kelengkapannya $81 \%$ dan yang tidak lengkap 19\%. Pada catatan yang baik terdapat persentase yang terendah yaitu pada item tidak ada bagian yang kosong sebesar $45 \%$, dan presentasi kelengkapan tertinggi pada item tidak ada tipe-x sebesar $100 \%$.

Berdasarkan hasil penelitian Dwinta Septanty 2016 Tinjauan Analisis Kuantitatif Resume Medis Pasien Rawa Inap Dalam Mempersiapkan Akreditasi Versi Kars 2012 Di Rumah Sakit Umum Kabupaten Tangerang Periode Juli 2016 memiliki rata-rata kelengkkapannya sebesar $96,70 \%$ dan ketidaklengkapannya sebesar 3,30\%. Berdasarkan 4 komponen analisis kuantitatif resume medis, komponen yang tertinggi kelengkapannya adalah identitats pasien sebesar 100\% dan komponen yang terendah kelengkapannya adalah isi resume medis sebesar 90\% (Septanty, 2016). 
Berdasarkan hasil pembahasan dalam penelitian ini dapat disimpulkan bahwa kelengkapan pengisian formulir resume medis yang ditinjau dari 24 item, terdapat 13 item yang terisi lengkap (54\%) serta 11 item yang tidak terisis lengkap (46\%) dilihat dari data formulir resume medis yang di analisis, sehingga angka ketidaklengkapan di RSUD Toto Kabila masi kurang baik karna belum sesuai dengan standar angka kelengkapan yang diterapkan Depkes RI 2008 tentang Standar Pelayanan Minimal Rumah Sakit untuk kelengkapan $100 \%$, hal ini bisa saja dipengaruhi oleh tersedianya tenaga rekam medis di RSUD Toto Kabila yang belum mencukupi baik ditinjau dari segi jumlah maupun dari segi kompotensi tenaga perekam medis (Saud, 2017).

Berdasarkan permenkes RI no. 129 tahun 2008 tentang standar Pelayanan Minimal Rumah Sakit yaitu kelengkapan pengisian resume medis 1x24 jam setelah pelayanan harus $100 \%$. Analisis kuantitatif dilakukan berdasarkan 4 komponen yaitu identifikasi pasien, kelengkapan catatan yang penting, autentikasi penulis, catatan yang baik (RI, 2008).

\section{Dampak Ketidaklengkapan Resume Medis}

Berdasarkan hasil wawancara dengan petugas rekam medis terdapat dampak dari resume medis yang tidak lengkap adalah:

Angka review rekam medis yang tidak bagus karena resume medis yang tidak lengkap. Berdasarkan Permenkes RI No. 129 Tahun 2008 tentang standar Pelayanan Minimal Rumah Sakit yaitu kelengkapan pengisian resume medis 1 x24 jam setelah pelayanan harus $100 \%$.

Tidak bisa mengklaim bpjs khusus pasien bpjs Persyaratan pengajuan klaim manfaat pelayanan kesehatan di FKTP yaitu adanya kelengkapan khusus yang terdiri dari bukti pelayanan yang sudah ditandatangani oleh Peserta atau anggota keluarga, dan kelengkapan pendukung yang dipersyaratkan oleh masingmasing tagihan klaim.

Membuat proses kelanjutan pengobatan terganggu karna riwayat tidak dilengkapi Tujuan dibuatnya resume medis ini adalah : untuk menjamin kontinuitas pelayanan medik dengan kualitas yang tinggi serta sebagai bahan referensi yang berguna bagi dokter yang menerima, apabila apabila pasien tersebut dirawat kembali di rumah sakit, sebagai bahan penilaian staf medis rumah sakit, untuk memenuhi permintaan dari badan-badan resmi atau perorangan tentang perawatan seorang pasien, misalnya dari perusahaan asuransi (dengan persetujuan pimpinan), untuk diberikan tembusan kepada sistem ahli yang memerlukan catatan tentang pasien yang pernah merawat Resume medis tidak lengkap akan berpengaruh terhadap akreditasi rumah sakit.

Akreditasi Rumah Sakit yang selanjutnya disebut Akreditasi adalah pengakuan terhadap mutu pelayanan Rumah Sakit, setelah dilakukan penilaian bahwa Rumah Sakit telah memenuhi Standar Akreditasi. Apabila terdapat berkas resume medis tidak lengkap dapat berpengaruh ke mutu pelayanan rumah karna belum memenuhi standar akreditasi (RI, 2017).

Berdasarkan hasil penelitian Reza Geta Pratiwi 2019 dengan judul Tinjauan Kelengkapan Formulir Resume Medis dengan Regulasi SNARS di RSUD dr. Soedono Madiun dampak yang ditimbulkan dari tidak lengkapnya pengisian dokumen rekam medis yaitu isi dari rekam medis yang terkait dengan hasil pemeriksaan pasien tidak dapat dipertanggungjawabkan isinya jika terjadi suatu masalah yang akan berlanjut di jalur hukum, rumah sakit tidak dapat mempertahankan akreditasi SNARS yang sudah dicapinya karena kurangnya mutu pelayanan kepada pasien dan jika diagnosa tidak lengkap maka akan berdampak kepada pasien karena pasien tidak mengetahui apa diagnosa yang diberikan oleh dokter (Rsu \& Ponorogo, 2020).

\section{SIMPULAN}

Sudah terdapat Standar Prosedur Operasional (SPO) yang mengatur tentang pengisian resume medis di RSUD Kembangan Jakarta tetapi belum semua prosedur terlaksana, terdapat 3 point prosedur yang belum terlaksana yang dimana belum adanya buku catatan yang mencatat resume medis yang belum diisi dan pengisian resume medis yang masih dilaksanakan di ruang rawat inap. Analisis kuantitatif 90 resume medis didapatkan kelengkapan pada komponen Identifikasi Pasien 99,16\%, Catatan yang Penting 88,43\%, Autentikasi Penulis $97,77 \%$, dan Catatan yang Baik $81 \%$. Dampak dari ketidaklengkapan dari resume medis yaitu membuat angka review rekam medis menjadi tidak bagus, bagi pasien bpjs klaim menjadi terhambat, membuat proses kelanjutan pengobatan terganggu karna riwayat pengobatan pasien tidak lengkap, tidak lengkap resume juga 
berpengeraruh terhadap akreditasi rumah sakit. Saran yang dapat diberikan kepada RSUD Kembangan yaitu Perlunya dilakukan sosialisasi kembali mengenai Standar Prosedur Operasional pengisian resume medis kepada seluruh pelayan kesehatan (dokter dan perawat) mengenai prosedur SPO yang belum terlaksana agar dokter dan perawat melakukan prosedur pengisian resume medis sesuai dengan SPO pengisian resume medis dan mengisi kelengkapan pada resume medis khususnya pada komponen persentase yang terendah yaitu Catatan yang Baik Perlu ketegasan dari pihak Direktur Rumah Sakit agar dapat memberikan sanksi kepada dokter dan perawat yang bertanggung jawab bila tidak melengkapi resume medis, agar mengurangi dampak dari ketidaklengkapan resume medis melengkapi resume medis, agar mengurangi dampak dari ketidaklengkapan resume medis.

\section{DAFTAR RUJUKAN}

Ani, S. (2017). Tinjauan Kelengkapan Isi Rekam Medis Kasus bedah di Rumah Sakit Haji Pondok Gede Jakarta (p. 3). p. 3. Jakarta: Digilib Esa Unggul.

Hatta, G. R. (2014). Manajemen Informasi Kesehatan disarana Pelayanan Kesehatan (revisi 3; Gemala R.Hatta, Ed.). Universitas Indonesia.

Indonesia, P. (2009). Undang-Undang Republik Indonesia Nomor 44 Tahun 2009 Tentang Rumah Sakit.

Laka, P. R. (2017). Kelengkapan Pengisian Lembar Ringkasan Masuk Keluar Rawat Inap Kasus Bedah di Rumah Sakit Panti Wilasa Citarum Semarang. Retrieved from http://eprints.ums.ac.id/32431/23/02.

NASKAH PUBLIKASI.pdf diakses pada4/15/2019

RI, K. (2008a). Menteri Kesehatan Republik Indonesia Nomor 129 Tahun 2008 Tentang Standar Pelayanan Minimal Rumah Sakit (p. 287). p. 287.

RI, K. (2008b). Peraturan Menteri Kesehatan Republik Indonesia Nomor 269 Tahun 2008 Tentang Rekam Medis (p. 7). p. 7. Jakarta.
RI, K. (2017). Undang-Undang Republik Indonesia Nomor 34 Tahun 2017 Tentang Akreditasi Rumah Sakit. PLoS Neglected Tropical Diseases, 9(5), 1-14. Retrieved from https://doi.org/10.1016/j.tmaid.2020.10160 7\%0Ahttps://doi.org/10.1016/j.ijsu.2020.0 2.034\%0Ahttps://onlinelibrary.wiley.com/ doi/abs/10.1111/cjag.12228\%0Ahttps://doi .org/10.1016/j.ssci.2020.104773\%0Ahttps: //doi.org/10.1016/j.jinf.2020.04.011\%0Aht tps://doi.o

Rsu, D. I., \& Ponorogo, M. (2020). Jurnal Delima Harapan 2020 Jurnal Delima Harapan 2020. 7(September), 39-47.

Saud, N. P. (2017). Tinjauan Resume Medis Pada Berkas Rekam Medis Pasien Rawat Inap Di Rumah Sakit Umum Daerah (Rsud) Toto Kabila Kabupaten Bone Bolango Provinsi Gorontalo 20171. Prosiding Nasional SMIKNAS 2018 APIKES Citra Medika Surakarta, 10.

Septanty, D. (2016). Tinjauan Analisis Kuantitatif Resume Medis Pasien Rawa Inap Dalam Mempersiapkan Akreditasi Versi Kars 2012 Di Rumah Sakit Umum Kabupaten Tangerang Periode Juli 2016. Universitas Esa Unggul. 